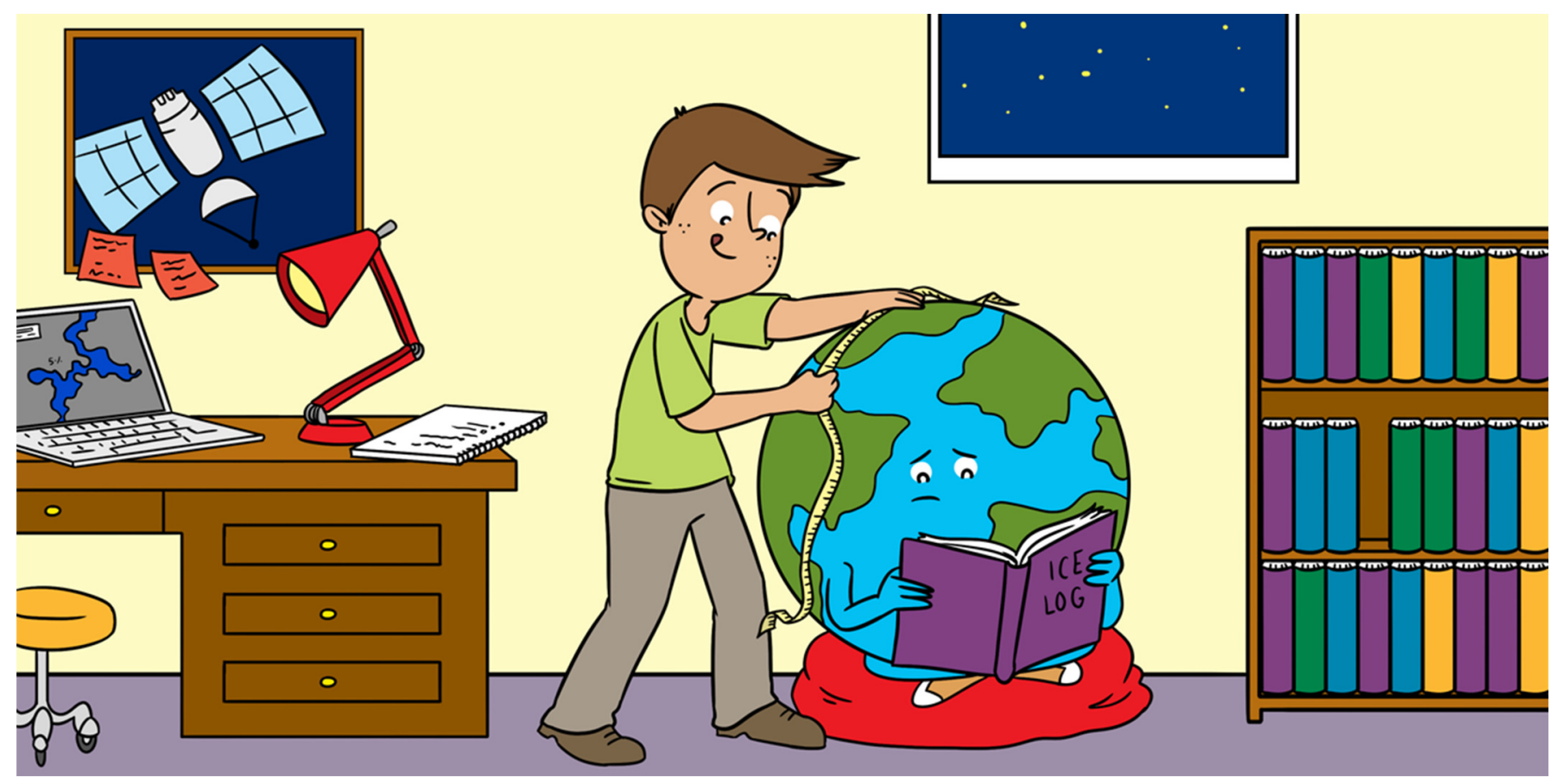

\title{
HOW DO WE TRACK CHANGING ARCTIC SEA ICE?
}

\section{Olivia Lee *}

International Arctic Research Center, University of Alaska Fairbanks, Fairbanks, AK, United States

YOUNG REVIEWER:

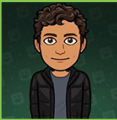

ARYAN

AGE: 15
Tracking changes in Arctic sea ice is an important way to understand how the Arctic is changing. This article explains how sensors on satellites can be used to track sea ice change, by measuring the energy given off by objects on earth. We will also explain some of the limitations of this method and describe other ways to track sea ice from old whaling ship records or from working with indigenous coastal communities. Used together, all of these methods can help us get a more complete picture of changing Arctic sea ice.

\section{WHY SHOULD WE CARE ABOUT MEASURING ARCTIC SEA ICE CHANGE?}

The amount of sea ice in the Arctic has been decreasing over recent years. We care about this for many reasons, but one important reason is that ice affects life in the Arctic. If there is less sea ice in the Arctic, walruses and seals have fewer resting places on the water. Less sea ice also affects the number of tiny plants, called ice algae, that live in the ice. These tiny plants are important food for other animals in the Arctic. Measuring sea ice also helps people in the Arctic understand 
PASSIVE

MICROWAVES

Low energy microwaves that are naturally emitted by objects, and can be passively detected by sensors.

NASA

National Aeronautics and

Space Administration the dangers of low sea ice conditions that can make it dangerous for people to travel over thin or unstable ice.

\section{HOW DO WE MEASURE CHANGING ARCTIC SEA ICE?}

Sea ice covers large areas of the Arctic, and the only way to see the whole Arctic is to look at it from space. Scientists today use tools on satellites to get a wide view of the sea ice over the Arctic. One satellite-based tool that scientists use measures a type of energy called passive microwaves. By measuring passive microwaves from space, scientists can tell where there is sea ice, and where there is land or water.

\section{WHAT ARE PASSIVE MICROWAVES AND HOW DO WE USE THEM?}

All objects on earth give out energy as microwaves. Microwaves are a type of low-energy radiation that is not related to the temperature of the object. Since all objects naturally radiate this energy they can be passively detected by sensors on satellites, hence the term: "passive microwaves." The low-energy microwaves can give us some information about the composition of the object they come from. The types of atoms in an object and how these atoms are arranged affects the energy they give out. For example, solid sea ice gives out more microwave energy compared with the ocean water around it. When the satellite data detects this higher energy area, it tells us that there is sea ice on the ocean. Clouds in the sky do not give out much microwave energy, and this makes it easy to "see through" the clouds to find sea ice using satellite equipment that can detect passive microwaves. This is an improvement over using satellites to take "regular" pictures of the earth in the visible light range, because when clouds cover the sky, visible light, which is the energy we can see with the naked eye, is blocked.

However, there are some problems with using passive microwaves to measure sea ice. Since the microwave energy given off by sea ice is so low, this tool is best used for measuring ice over large areas. This means that we can use passive microwaves to measure sea ice across the entire Arctic (Figure 1), but we have a harder time finding smaller details in the ice with this tool. For example, it is not easy to find leads, which are narrow breaks in sea ice where there is some open water. It can also be hard to measure sea ice with passive microwaves when there is very little ice. For example, when there is $<10 \%$ sea ice in the ocean, there can be mistakes in the ice measurements.

Satellites have helped us measure passive microwaves from sea ice since 1972. However, most scientists use satellite measurements starting from 1978. This was the year when NASA put a special sensor, 
Figure 1

Arctic sea ice measured from passive

microwaves in

September 2019 (white area). The pink line

shows where the

median ice edge was measured between the years 1981 and 2010 .

Source: National Snow and Ice Data Center.

\section{SCANNING}

MULTICHANNEL

MICROWAVE

RADIOMETER

(SMMR)

This is a type of sensor used in passive

microwave detection of sea ice from satellites.

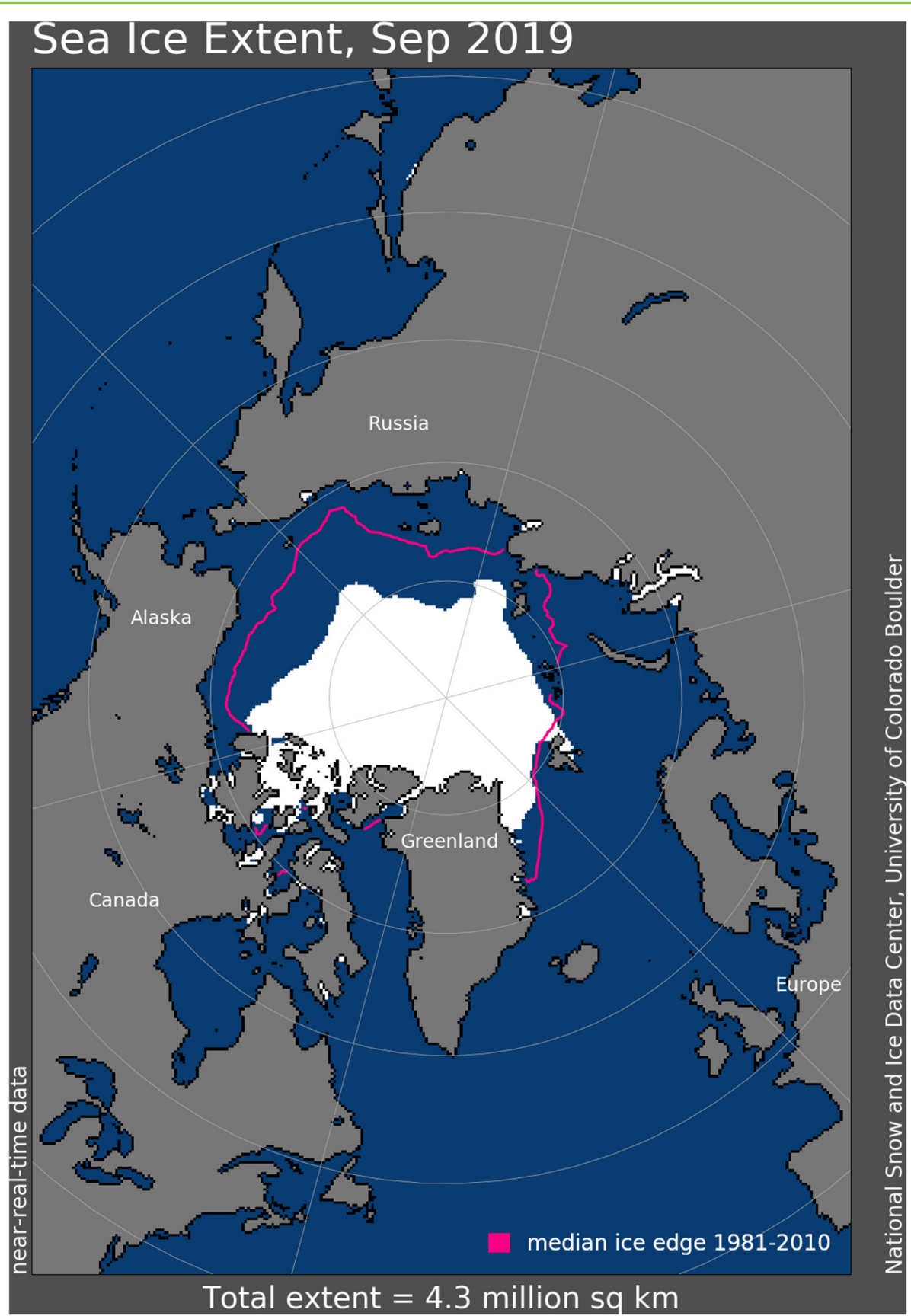

Figure 1

called the scanning multichannel microwave radiometer (SMMR), into operation to find sea ice.

\section{HOW ELSE CAN WE STUDY SEA ICE CHANGE?}

Since there are some problems with measuring sea ice by passive microwaves, scientists also study sea ice using other information. There are additional satellite tools that can be used to measure sea ice, but we will focus on a few non-satellite examples. 
Figure 2

Data from several sources can be combined to give a more complete picture of sea ice. The average amount of sea ice measured from passive microwaves is reported in red numbers. Sea ice concentration ranges from just over $0 \%$ in the blue squares to $100 \%$ in the white squares. The satellite photograph shows some cloud cover, which makes it difficult to see areas of sea ice. Coastal community reports of sea ice provide locations of walruses seen traveling with the sea ice (orange walrus icons).

\section{LIGHT DETECTION}

AND RANGING

(LIDAR)

This uses laser pulses as an active energy source and a sensor to that captures the returning light to measure distances.

\section{RADIO DETECTION}

AND RANGING

(RADAR)

This uses an active energy source to emit radio waves and a sensor that receives the returning radio waves to detect objects.

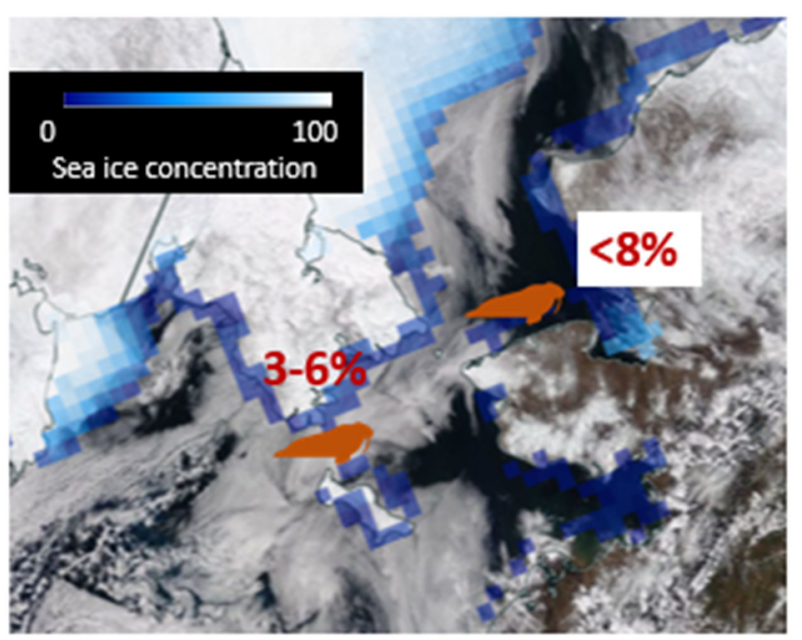

Figure 2

The Historical Sea Ice Atlas puts together information from different sources about where sea ice was found. Some information about sea ice goes back as far as 1850. Since this was long before modern satellites, scientists used old logbooks from whaling ships that reported sea ice conditions, and old maps that helped ships travel safely over the ocean.

Scientists also work together with native sea ice experts in coastal communities to measure changes in sea ice. Working with native experts, scientists can record when the sea ice starts to freeze or melt near the coast, and they can combine local expert information with what they know from satellites [1]. This is important because native experts can provide detailed information about the sea ice that is hard to obtain from satellite data. For example, native experts can tell us when and where breaks in the ice happen, they can describe the cause of large piles of ice (called ice ridges), and they can also describe when animals, such as walruses, are seen as these animals travel north with the ice during spring (Figure 2).

\section{WHAT ARE SOME OTHER EXAMPLES OF SATELLITE TECHNOLOGY TO MEASURE SEA ICE CHANGE?}

A comparison of different satellite technologies that are used to detect sea ice is shown in Figure 3. Some methods use passive energy that is reflected from objects on earth, and these methods include using visible light or passive microwaves, as described earlier. Other techniques, such as light detection and ranging (LIDAR) and radio detection and ranging (RADAR), use active energy pulses to detect characteristics of sea ice. LIDAR uses lasers as an active energy source, while RADAR uses radio wave energy. "Active" means that energy is sent out of a platform-which could be an airplane or satellite, to bounce off objects on the earth. Then, the energy that bounces back 
Figure 3

Ways that sensors on satellites can detect sea ice. (Top) Visible light from the sun is reflected off objects on earth and can be detected by satellites, in the form of photographs, but this is affected by cloud cover. (Middle) Passive microwave energy naturally emitted by all objects on earth can be detected by satellites.

The level of energy detected tells scientists about the type of object emitting it. (Bottom) A satellite can emit active pulses of lasers (LIDAR) or radio waves (RADAR) that are then reflected back by surfaces on earth and captured by the satellite sensors.

\section{ICESat2}

Ice, Cloud, and land Elevation Satellite 2.

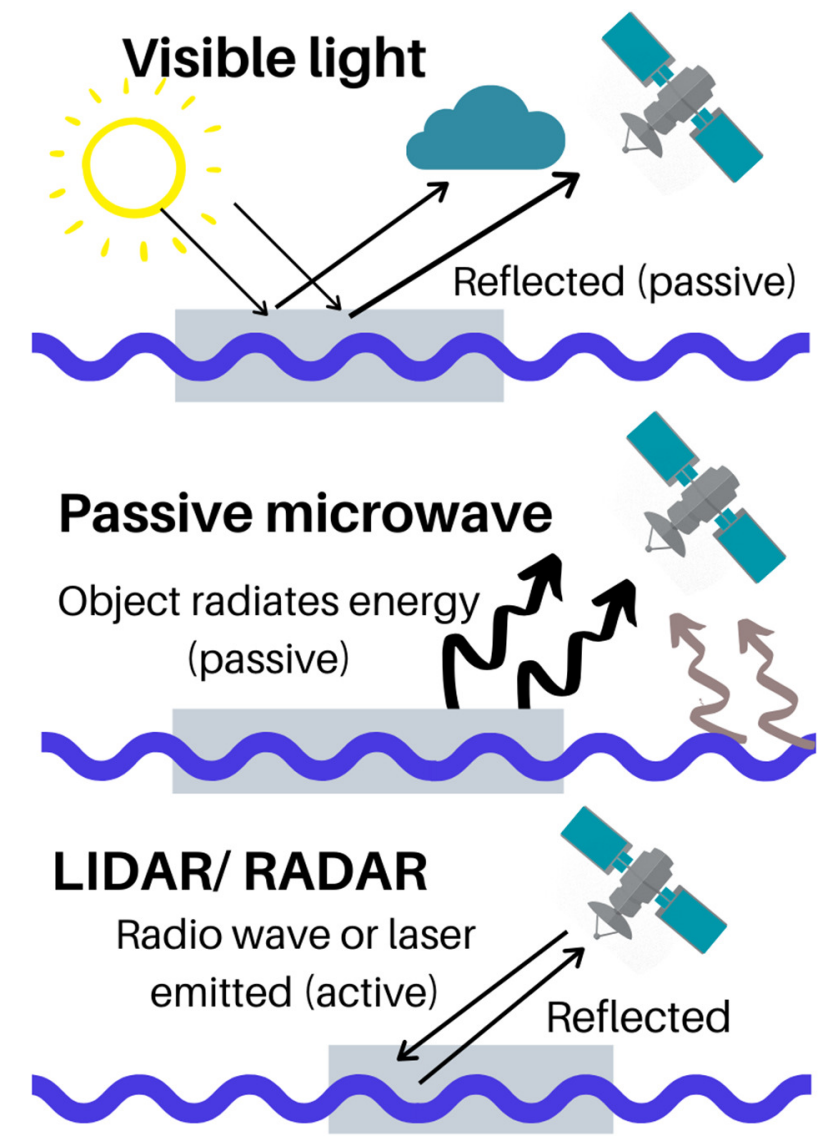

Figure 3

to the platform is detected by sensors. The recently launched NASA ICESat2 satellite is an example of an active ice detection technique using LIDAR, in which laser beams from the satellite are used to look at sea ice thickness (NASA has more information on the laser technology here). As laser pulses emitted from the ICE-Sat2 satellite hit the surface of the earth, the number of returning photons (particles of light), and the time it takes for these photons to travel back to the satellite is used to calculate the distance between the satellite and the earth's surface. Knowing the distances between the satellite and the sea ice surface or open water, it is possible to calculate the height of the sea ice above sea level. Such technological advancements help us look at sea ice thickness, and not just sea ice cover. However, the narrow beams of the lasers are only able to capture snapshots of relatively small areas of sea ice at any given time, just as a beam of light from a flashlight can only illuminate the small areas of the dark that you point the light at.

\section{IMPORTANCE OF OBSERVING SEA ICE}

Sea ice is a core component of polar regions that has been changing rapidly over the last decade. We use a range of high-tech tools, such as satellite detections of passive microwaves, but 
also collaborations with native communities to observe and track how quickly the Arctic is changing. This information can then be used to help people plan how to adapt and respond to rapid Arctic change.

\section{REFERENCES}

1. Johnson, M., and Eicken, H. 2016. Estimating Arctic sea-ice freeze-up and break-up from the satellite record: a comparison of different approaches in the Chukchi and Beaufort Seas. Elem. Sci. Anth. 4:000124. doi: 10.12952/journal. elementa.000124

SUBMITTED: 30 October 2019; ACCEPTED: 17 April 2020; PUBLISHED ONLINE: 22 May 2020.

EDITED BY: Christian März, University of Leeds, United Kingdom

CITATION: Lee O (2020) How Do We Track Changing Arctic Sea Ice? Front. Young Minds 8:68. doi: 10.3389/frym.2020.00068

CONFLICT OF INTEREST: The author declares that the research was conducted in the absence of any commercial or financial relationships that could be construed as a potential conflict of interest.

COPYRIGHT $\odot 2020$ Lee. This is an open-access article distributed under the terms of the Creative Commons Attribution License (CC BY). The use, distribution or reproduction in other forums is permitted, provided the original author(s) and the copyright owner(s) are credited and that the original publication in this journal is cited, in accordance with accepted academic practice. No use, distribution or reproduction is permitted which does not comply with these terms.

\section{YOUNG REVIEWER}

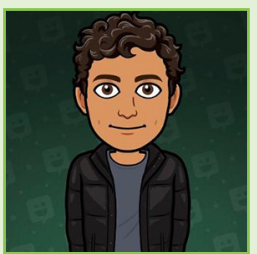

\section{ARYAN, AGE: 15}

Aryan is a budding learner who enjoys reading about scientific advancements especially in the field of climate change and energy. Outside the classroom, Aryan is a fabulous football player full of energy and gusto. One day, he hopes that Manchester United can win the English Premier League, although if they go on losing to Newcastle, that day is far away!

\section{AUTHOR}

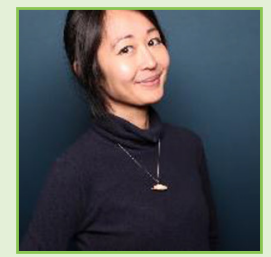

\section{OLIVIA LEE}

Olivia is a researcher at the International Arctic Research Center in the University of Alaska Fairbanks. She is interested in studying Arctic marine ecosystem change, and she frequently collaborates with Indigenous Alaska experts living along the coast to understand how sea ice change affects marine mammal distributions in 
the northern Alaska. Her work is interdisciplinary and includes scenarios research on how physical environmental change, Arctic development activity, and ecosystem change co-evolves in ways that are not easy to predict. *oalee@alaska.edu 